\title{
Reflü Cerrahisi Sonrası Görülen Basınçlı Hidropnömotoraks*
}

\section{Tension Hydropneumothorax after Anti-Reflux Surgery}

Öz

Gastroözefageal reflü için uygulanan cerrahi tedavilerden biri olan Nissen fundoplikasyonu, minimal invaziv olması, hastada daha az ağrıya yol açması ve daha kısa süreli hospitalizasyon gerektirmesi nedeniyle yaygınca uygulanmaktadır. Ancak komplikasyon oranı oldukça düşük olmasına rağmen ölüme neden olabilecek tansiyon pnömotoraks gibi bir klinik durum ortaya çıkabilmektedir. Hastamızda reflü cerrahisi (Nissen fundoplikasyonu) sonrası tansiyon pnömotoraks ve sonrasında hidrotoraks gelişmiştir. Bu gibi komplikasyonlar hastanede kalış süresini uzatmakta, morbiditeyi artırmaktadır. Laparoskopik cerrahi işlemler kolay ve yaygın uygulamalardır; intraoperatif ve postoperatif komplikasyonlar açısından erken tanı önemlidir.

Anahtar Sözcükler. Gastroözefageal reflü; tansiyon pnömotoraks; dekortikasyon

\section{Abstract}

Nissen fundoplication, one of the surgical procedures applied to treat gastroesophageal reflux is performed commonly because it is minimally invasive, causes the patient less pain, and requires shorter hospitalization. However, despite the low complication rate some patients may develop tension pneumothorax, a clinical condition that can be fatal. After reflux surgery (Nissen fundoplication), our patient develop tension pneumothorax and then hydrothorax. Such complications lead to prolonged hospitalization and increased morbidity. Laparoscopic surgical procedures are practical and common interventions; and early diagnosis is important for intraoperative and postoperative complications.

Keywords: Gastroesophageal reflux; tension pneumothorax; decortication
Murat Öncel, Güven Sadi Sunam, Hüseyin Yıldıran, Kübra Altıntaş

Selçuk Üniversitesi, Tıp Fakültesi, Göğüs Cerrahisi Anabilim Dalı, Konya, Türkiye

Geliş Tarihi /Received : 02.05.2016 Kabul Tarihi /Accepted: 20.11.2016

DOI: 10.21673/anadoluklin.180826

Sorumlu Yazar/Corresponding Author Murat Öncel

Selçuk Üniversitesi, Selçuklu Tıp Fakültesi, Göğüs Cerrahisi Anabilim Dalı Konya, Türkiye

E-mail:moncel01@hotmail.com

* Türk Toraks Derneği 17. Ylllık Kongresi’nde (2-6 Nisan 2014, Antalya) poster olarak sunulmuştur. 


\section{GiRiş}

Antireflü operasyonları günümüzde kolay ve minimal invaziv olmaları nedeniyle yayginca uygulanmaktadır. Bu operasyonlarda yüksek komplikasyon oranı cerrahın tecrübe eksikliği nedeniyle oluşmaktadır. Bazen bu komplikasyonlar sonucunda ölüm dahi görülebilmektedir. Pnömotoraks, laparoskopik Nissen fundoplikasyonu sonrası gelişebilen bir komplikasyondur (1). Bu komplikasyonun görülme sıklığı \%1'dir ve genellikle solda olmakla birlikte tecrübeli ellerde daha da azalmıştır (2). Olgumuz, antireflü cerrahisi sırasında kullanılan medikal gazlar sonucu gelişen tansiyon pnömotoraks ve onun sonucu olarak gelişen hidrotoraks nedeniyle ilginçtir.

\section{OLGU SUNUMU}

Otuz dokuz yaşındaki erkek hasta, dış merkezde gastroözefageal reflü şikayeti olması nedeniyle genel cerrahi kliniğine başvurmuş. Hastaya laparoskopik Nissen fundoplikasyonu operasyonu planlanarak uygulanmış. Operasyonunun hemen sonrasında postoperatif erken dönemde solunum sıkıntısı gelişmiş. Preoperatif çekilen akciğer grafisi normal olan hastanın operasyon sonrası çekilen direkt akciğer grafisinde solda tansiyon pnömotoraks ve hava sıvı seviyesi veren plevral sıvı görülmesi üzerine acil tüp torakostomi uygulanmış (Resim 1). Dış merkezde klinik takiplerinde akciğerin ekspansiyon sorunu olması üzerine ikinci toraks tüpü takılmış. Hasta, yirmi günlük klinik takipte solunum sıkıntısının gerilememesi ve akciğer grafisinde radyolojik düzelme ve akciğer ekspansiyonu sağlanamaması nedeniyle kliniğimize nakledildi (Re$\operatorname{sim} 2$ ). Kliniğimize kabulü yapıldığında genel durumu orta olan hastada takipne, taşikardi ve dispne mevcuttu; ancak hastanın genel durumu stabildi. Sol hemitoraksta solunum sesleri azalmıştı. İki toraks tüpünde de hava kaçağı vardı. Hastanın toraks drenlerinden biri alındı. Plevral sıvıdan kültür ve biyokimya örnekleri alındı. Plevral sıvının eksüda vasfında olduğu görüldü; kültürde bakteri üremesi olmadı. Non-spesifik antibiyotik tedavisine başlandı. Gastrointestinal perforasyon olasılığını değerlendirmek için özefagus, mide, duodenum pasaj grafisi çekildi, patoloji görülmedi. Toraks tomografisinde akciğerin tam ekspanse olmadığı, plevrada kalınlaşma olduğu görüldü (Resim 3). Has-

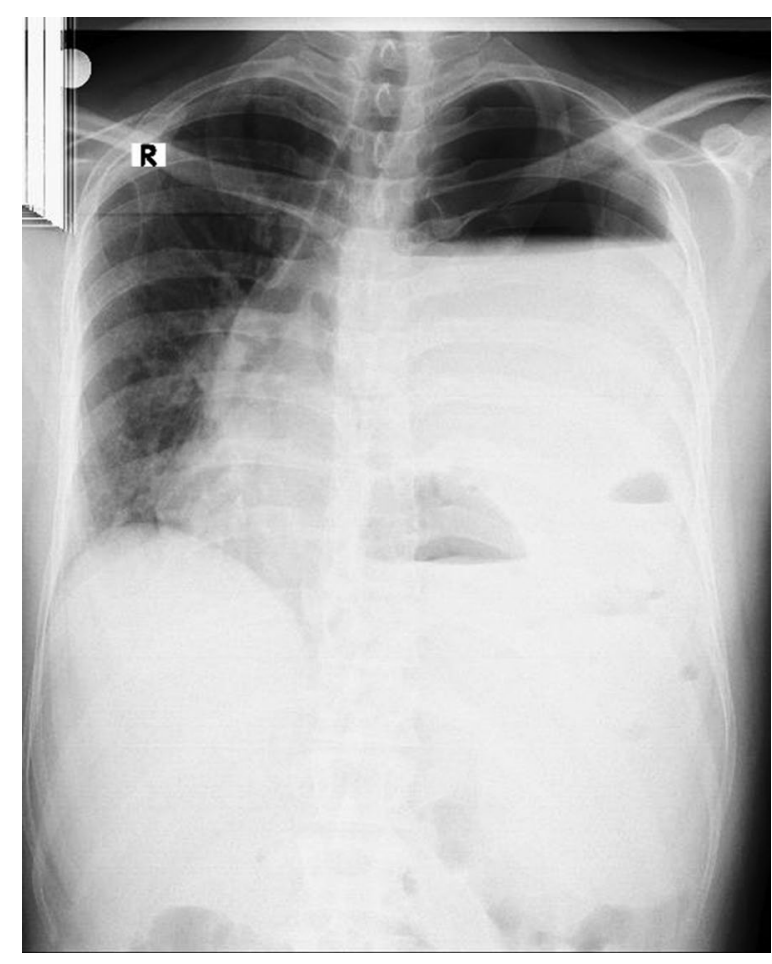

Resim 1. Reflü cerrahisi sonrası çekilen direkt akciğer grafisinde solda tansiyon pnömotoraks ve hava sıvı seviyesi veren plevral efüzyon.

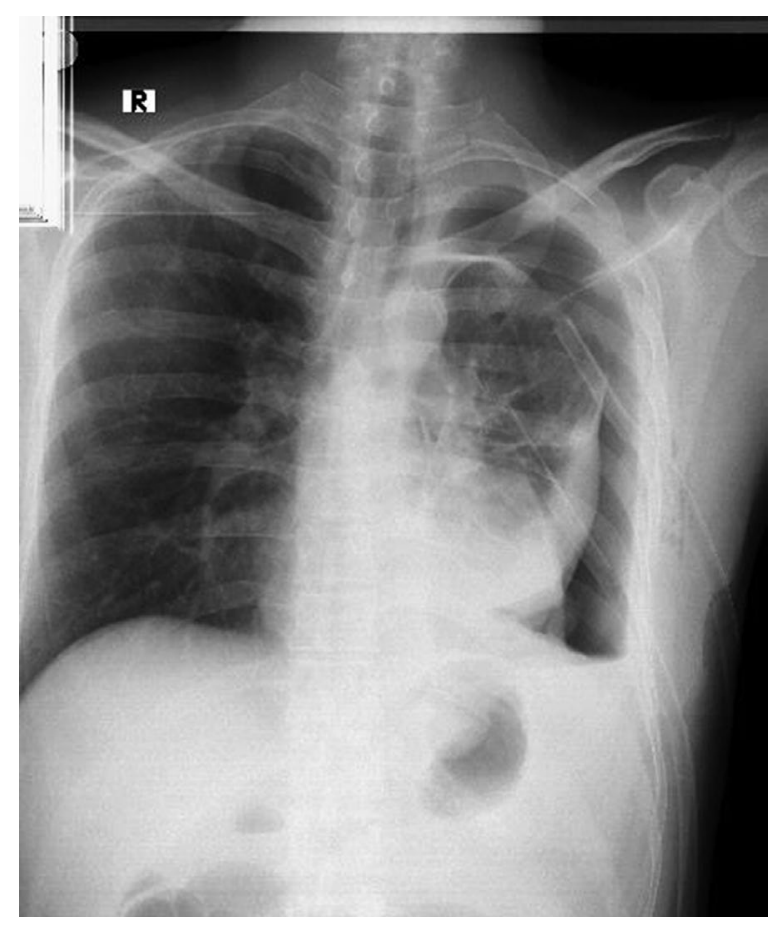

Resim 2. İki göğüs tüpü uygulanmasına rağmen ekspansiyonu sağlanamamış akciğer dokusu.

taya dekortikasyon planlandi. Hasta sol torakotomi ile operasyona alındı. Gözlemde plevranın ileri derece yapışık ve kalınlaşmış olduğu, diyafragmanın intakt 


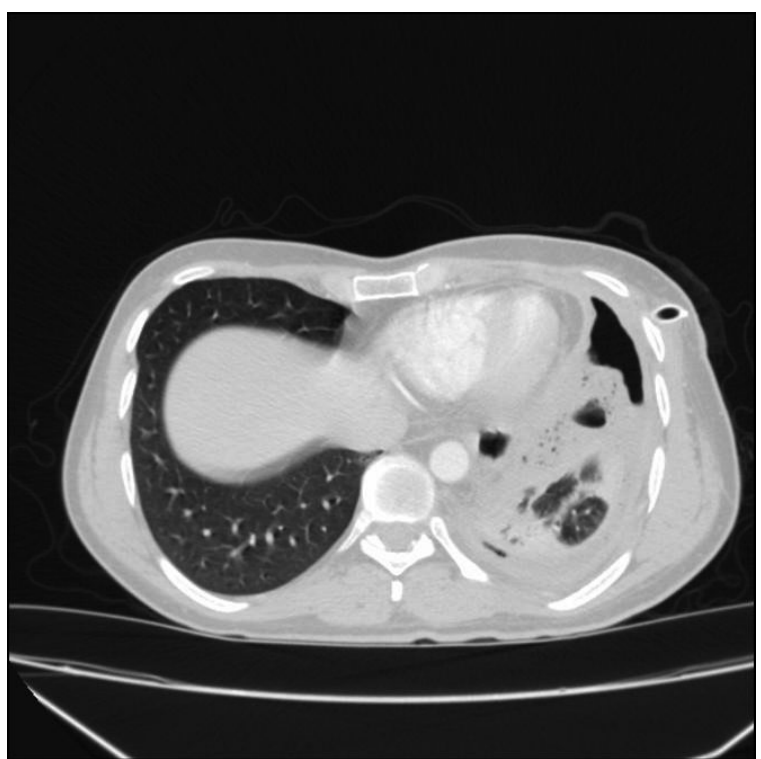

Resim 3. Hastanın bilgisayarlı toraks tomografisi.

olduğu ancak diyafragma yüzeyinin de kalınlaşmış olduğu görüldü. Total dekortikasyon yapılarak toraksa iki adet dren konduktan sonra operasyon sonlandırıld. Hava kaçağ 1 kesilen hasta toraks drenleri alınarak operasyondan sonraki 15. günde taburcu edildi (Resim 4). Plevradan alınan multipl biyopsilerin patoloji sonucu ülserasyon, iltihabi granülasyon dokusu ve yabancı cisim reaksiyonu olarak geldi.

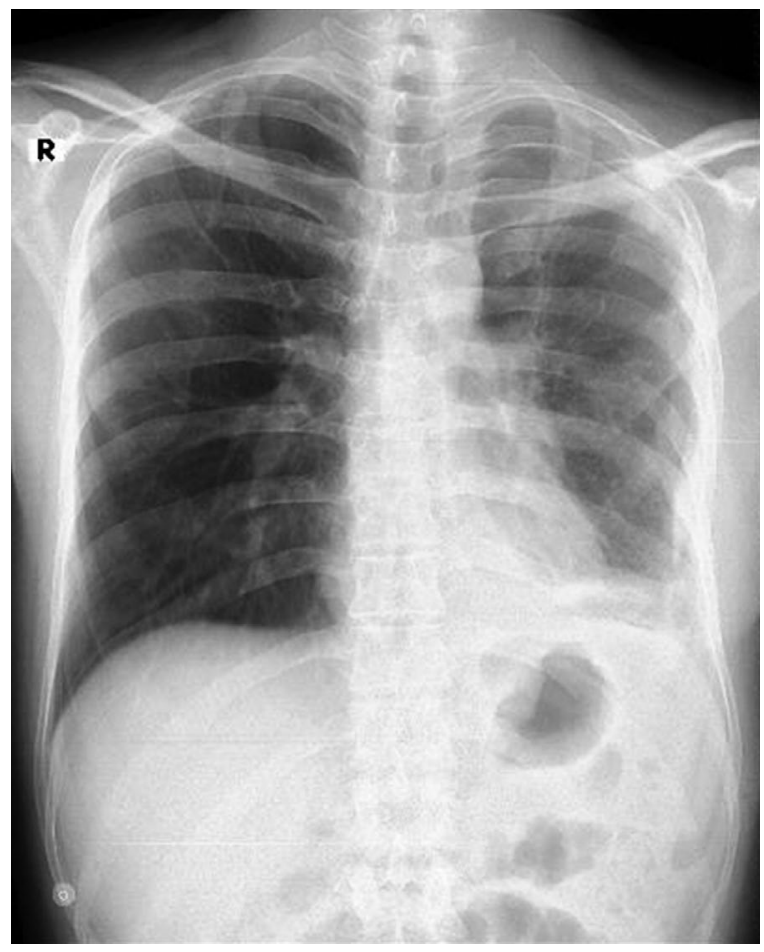

Resim 4. Hastanın taburculuğu öncesi çekilen PA akciğer grafisi.

\section{TARTIŞMA VE SONUÇ}

Laparoskopik antireflü ameliyatlarından sonra gelişen tansiyon pnömotoraksin etiyolojisinde plevranın özefageal hiatus çevresinde yapılan diseksiyon sırasında hasara uğradığı görülür. Tansiyon pnomotoraks ise batına verilen karbondioksit gazının diyafragmatik porlar ve hiatus aracılığıyla torasik kaviteye kaçması ile olmaktadır (2). Bir diğer kabul edilebilir neden ise embriyonal fazda diyafragmada bulunan potansiyel kanalların açık kalması, peritoneal kavitedeki basınç arttığı zaman bu kanalların açılmasıdır. Bunlara ilaveten, akciğerdeki büllerin patlaması da altta yatan nedenlerden biri olarak görülmektedir $(3,4)$. Bu da cerrahi sonrası uzamış hava kaçağını açıklayabilir. Laparoskopik hiatal herni ve antireflü operasyonları, daha az ağrıya yol açmaları, daha kısa hastanede kalış ve sınırlı bir kesi gerektirmeleri nedeniyle avantajlıdır. Karbondioksit gazının hastalarda pnömotoraks oluşturacağ 1 göz önüne alınarak hastalarda mutlak monitörizasyon, nabız oksimetresi ile yakın takip ve desatürasyon halinde erken müdahale önerilmektedir (2). Laparoskopik cerrahide karbondioksit gazının ekstravaze oluşu iyi tanımlanmış ve ender görülen komplikasyonlardandır (5). Birçok hastada pnömotorakslar tolere edilebilmekte ve oksijen tedavisi ile ekspanse olabilmektedir. Ayrıca bir hafta içinde bu pnömotorakslar rezorbe olmaktadır. Akciğerin ekspansiyonunu zorlaştıran nedenlerden biri de plevral kalınlaşma olmaktadır. Bu durum tuzak akciğer oluşturarak akciğer parankiminin kompliyansını etkilemektedir. Bazen de geç dönemde teşhis edilen pnömotorakslarda ekspansiyon problemleri ve ampiyem gibi hastanede kalış süresini uzatan ileri komplikasyonlar ortaya çıkmaktadır (6). Nissen fundoplikasyonunda operasyon süresinin uzun olması ve yüksek basınçlı $\mathrm{CO}_{2}$ kullanımı pnömotoraks gelişme riskini artırmaktadır (4).

Sonuç olarak laparoskopik fundoplikasyon esnasında sıklıkla pnömotoraks gelişmektedir. Önerimiz dikkatli bir monitörizasyon uygulamak ve desatürasyon durumlarında özellikle tansiyon pnömotoraks kliniği oluşması halinde intraoperatif tüp torakostomi uygulayarak akciğeri ekspanse edebilmektir. Geç tanı almış hastalarda ise videotorakoskopi, altta yatan nedenin tespiti ve uygun cerrahi müdahalenin belirlenişi için uygulanmalıdır. 


\section{KAYNAKLAR}

1. Mangar D, Kirchhoff GT, Leal JJ, Laborde R, Fu E. Pneumothorax during laparoscopic Nissen fundoplication. Can J Anaesth. 1994;41(9):854-6.

2. Joris JL. Anesthesia for laparoscopic surgery. Miller's Anesthesia, 6. ed., ed. Miller RD. Philadelphia: Churchill Livingstone; 2004:2285-306.

3. Murdock CM, Wolff AJ, Van Geem T. Risk factors for hypercarbia, subcutaneous emphysema, pneumothorax, and pneumomediastinum during laparoscopy. Obstet Gynecol. 2000;95(5):704-9.
4. Richard HM 3rd, Stancato-Pasik A, Salky BA, Mendelson DS. Pneumothorax and pneumomediastinum after laparoscopic surgery. Clin Imaging. 1997;21(5):337-9.

5. Mullett CE, Viale JP, Sagnard PE, Miellet CC, Ruynat LG, Counioux HC, et al. Pulmonary $\mathrm{CO} 2$ elimination during surgical procedures using intra- or extraperitoneal $\mathrm{CO} 2$ insufflation. Anesth Analg. 1993;76(3):622-6.

6. Collazo E, Díaz Iglesias C. Iatrogenic perforation of the intrathoracic colon after a late traumatic diaphragmatic hernia [İspanyolca]. Rev Esp Enferm Dig. 1994;86(4):767-70. 